\title{
Sciendo
}

(日)

studia humana
Studia Humana

Volume 10:1 (2021), pp. 41-50

DOI: $10.2478 / \mathrm{sh}-2021-0004$

\section{Reply to Walter Block on Ethical Vegetarianism}

\author{
Michael Huemer \\ University of Colorado \\ Boulder, CO 80309 \\ United States
}

\begin{abstract}
:
I address Walter Block's recent criticisms of my book, Dialogues on Ethical Vegetarianism. Methodologically, Block relies too much on appeals to contentious and extreme assumptions. Substantively, most of his objections are irrelevant to the central issue of the book. Those that are relevant turn on false assumptions or lead to absurd consequences. In the end, Block's claim to oppose suffering cannot be reconciled with his indifference to a practice that probably causes, every few years, more suffering than all the suffering in human history.

Keywords: vegetarianism, veganism, libertarianism
\end{abstract}

\section{Introduction}

In a recent issue of Studia Humana, economist Walter Block has advanced a spirited critique of my book, Dialogues on Ethical Vegetarianism. ${ }^{1}$ Block raises a dizzying array of objections, too numerous and varied for me to address all of them here. Fortunately, many of them are beside the point of my book. I have in mind where Block advocates legalizing insider trading [1, p. 60], criticizes my use of "them" [1, p. 60], discusses ending trade with China [1, p. 58], and so on. In addition, some of Block's remarks are very difficult to make sense of on their face, such as his suggestion that there is no way of knowing whether a cure for cancer would be more valuable than a brief episode of sadistic pleasure for two boys [1, p. 55]. I shall pass over these points.

In what follows, I shall critique Block's philosophical methodology, then address some of Block's more relevant objections, then conclude by examining Block's view of the evil of suffering.

\section{Methodological Points}

\subsection{The Argument from Libertarianism}

Walter Block and I have two main methodological differences. First, among Block's preferred forms of argument is what I call "the Argument from Libertarianism," which consists of appealing directly to 
"libertarianism" to establish a philosophical point. There are two variants of this argument form. First, the Positive Argument from Libertarianism:

Libertarianism says that $\mathrm{P}$.

Therefore, $\mathrm{P}$.

For example, Block tells us, "In this philosophy [viz., libertarianism] the only crimes are those with (human) victims." Nor is Block merely avowing his own beliefs. He criticizes me more than once for not arguing in libertarian-typical ways or taking sufficiently libertarian positions [1, pp. 54, 59-60, 62].

Despite being a libertarian myself, I find this argument form not at all persuasive. I do not accept any position simply because it is the libertarian position. I first figure out what I believe about a variety of philosophical issues, then look for labels to describe my views. I call myself a libertarian because that term happens to correspond to my political views. I do not first decide that I'm a libertarian and then adjust my views to make sure that the label fits me; that would be irrational. If it should turn out that I endorse some libertarian views and some non-libertarian views, that is of no concern to me.

One must of course hold a consistent set of beliefs. But there is no inconsistency in holding libertarian views about some issues but not others. For instance, there is nothing inconsistent in supporting gun rights, capitalism, and ethical vegetarianism - regardless of whether the last position counts as "libertarian" or not. If Block is right (I don't think that he is) that libertarianism only recognizes crimes with human victims, then so much the worse for libertarianism; that gives us no evidence at all that only human victims matter morally.

The other form of the Argument from Libertarianism is even less cogent. I call it the Negative Argument from Libertarianism:

Libertarianism doesn't say that P.

Therefore, who cares about P?

For instance, Block avers that he does not care whether it is unethical for a large corporation to drive a small company out of business, because libertarianism doesn't say anything about that [1, p. 54]. He goes on to explain that libertarians qua libertarians are "not at all interested" in whether torturing animals is morally alright, since libertarians only care about the question of what constitutes just law $[1$, p. 55] (plus, to a small degree, whether initiation of force is alright $[1$, p. 54]).

I find this bizarre. If Block were completely uninterested in moral questions, I could at least understand that, for that is how psychopaths are. But he avows interest in one type of ethical question: the question of when it is morally acceptable to coercively punish someone for some action. He allegedly doesn't care about any other kind of wrong, or any other problem, besides the problem of unjust law (or lack of law) - because that, in Block's view, is what libertarianism is about. (But see section 4 below for contrary indications.)

Imagine a libertarian hospital run by Walter Block's cousin, Doctor Joe Block. A patient comes to see Dr. Block about a medical problem:

Patient: Doctor, I'm feeling a pain in my chest.

Block: Was it caused by force or fraud?

Patient: What? Of course not.

Block: Then stop complaining and go home.

Patient: But I think I might be having a heart attack!

Block: Having a heart attack and not having a heart attack are both compatible with libertarianism. So, as a libertarian, I am not at all interested in that. 
Now the point of this mini-dialogue is not to discuss the duties of doctors. Here is the point: many things are extremely important, even if they are not addressed by one's preferred political ideology. To declare that one does not care about any problem that is not addressed by one's ideology is simply not a reasonable position.

As I noted in the Dialogues, 74 billion animals are slaughtered on factory farms every year, worldwide. All or nearly all of them have lives of extreme suffering before their deaths, suffering of a sort that we would unhestitatingly dub "torture" if it were deliberately inflicted on any human being. Now, the total number of humans who have ever lived on Earth is estimated to be about 110 billion. Thus, as shocking as this statement might initially sound, it is completely plausible that just a few years of factory farming causes a greater total quantity of suffering than all the human suffering in all of history. Note that Walter Block does not dispute any of these facts. To react to such a problem with indifference would be a shockingly nihilistic stance.

Perhaps Block's point is not that he does not care about such problems, but that libertarianism per se does not care about such problems. But of what interest is that to ordinary, conscientious human beings? Imagine modifying the above dialogue so that Dr. Block's last line reads:

Block: Having a heart attack and not having a heart attack are both compatible with libertarianism. So libertarianism per se does not care about that.

Whereupon Dr. Block declines to do anything about the patient's symptoms. Block's remark may be true, but it is not a reasonable reaction to the patient's problem.

\subsection{Extremism}

Here is the other main methodological difference between Block and myself: Block believes that thinkers should take up extreme, unqualified generalizations with high confidence. Thus, he criticizes me for failing to advance strong, confident claims about rights as other libertarians do [1, p. 62] and for allowing exceptions to my advocacy of vegetarianism [1, p. 54]. On the other hand, he praises me for taking the seemingly extreme view that factory farming has caused more suffering than all the suffering in human history [1, p. 57-8].

To Block, my intellectual style must seem inconsistent: sometimes I am admirably bold, while at other times I am disappointingly modest. Let me explain why this seeming inconsistency occurs: it is because I am not trying to produce either bold or modest statements per se; I am trying to produce true and relevant statements. I of course prefer that the mode of expression of my views should be entertaining, so that more people will read them. But I do not adjust the content of my beliefs to enable me to make more exciting, brave, or otherwise fun statements.

The problem with extreme, sweeping generalizations is that they are nearly always false. If we are seeking the truth, then, we should try to avoid such statements as much as possible, compatible with still addressing the important issues. That has been my approach in political philosophy, and that was my approach to ethical vegetarianism. In both cases, I try to build my key conclusions on the most modest, least controversial premises possible. That is not a weakness; that is simply trying to seek the truth reliably.

\section{Objections to the Case for Ethical Veganism}

In this section, I address nine objections that Block raises to my ethical argument for veganism. 


\section{1. "Suffering Can Be Good"}

My central case for veganism turns on the vast pain and suffering caused by human consumption of animal products. But Block argues that pain and suffering can sometimes be good. Masochists, he says, desire suffering as an end in itself $\left[1\right.$, p. 54]. ${ }^{2}$ In addition, suffering inflicted as part of just punishment is morally good [1, p. 60-61].

Neither of these points is relevant. Animals on factory farms are not sexual masochists playing an enjoyable sexual game with the farm workers. They also are not guilty of any wrongdoing, so their suffering is not part of just retribution for anything. We do not need to figure out whether retributivism in the theory of punishment (the view that suffering for the blameworthy is intrinsically morally good) is correct, because, whether or not retributivism is true, no one thinks it applies to the case of animals on factory farms.

Block might say that he is criticizing my thesis that all pain and suffering is bad no matter what. But I never advanced any such thesis. (Again, I tend to avoid simplistic, unqualified generalizations.) My claim is that torturing animals on factory farms for the sake of trivial benefits for yourself, in the way that we are doing in actual reality, is wrong. Block has not attempted to identify any reason why that might be acceptable.

\section{2. "Rights Require Homesteading”}

Block holds that in order to possess rights, one must "homestead" one's rights by petitioning for them. (We can leave aside exactly what counts as homesteading, since any reasonable interpretation will make this false.) Animals presumably cannot petition for rights since they cannot speak. By the same token, however, infants and certain severely mentally disabled people cannot petition for rights either. So it would seem to follow, on Block's view, that torturing babies and severely retarded people is permissible. It is hard to think of a clearer reductio ad absurdum of a moral view.

In response, Block approvingly quotes Murray Rothbard, stating that babies are "future human adults." Neither Block nor Rothbard explain how this is supposed to be relevant. In any case, this does nothing to address the problem of severely retarded humans, who will never acquire normal intelligence and will never petition for anything.

Block then tries another gambit: he says "we go by species, not individual, membership." He gives no further explanation or justification; that is the entire argument. The assertion seems to be that babies and the mentally disabled have rights because other members of their species have homesteaded things. Block makes no effort to explain why species classifications are morally special but not genus classifications, race classifications, hair color classifications, or any other grouping - nor, indeed, why the moral rights of an individual would depend upon a grouping of that being with any other entities at all, rather than on the actual characteristics of that individual.

Let's think about land ownership. This is the source of Block's idea of homesteading, and Block invites us to take land ownership as the model for all rights. But land ownership certainly does not work in the way that Block and Rothbard require: I do not own a plot of land because I could homestead it in the future, or because someone else homesteaded it, or because other members of my species homesteaded other things. The way homesteading works is that the individual who actually homesteads a plot of land acquires that specific plot of land and nothing else. So again, on the homesteading theory, there is no basis for infants or severely disabled humans to have any rights. The idea that they have rights because they might homestead something in the future or because other conspecifics have homesteaded other things is a non-starter.

The homesteading theory is so problematic that you might assume that Block would not have asserted it without some powerful evidence for it. But then you would be mistaken. Block's argument 
for the theory is a particularly weak iteration of the Argument from Libertarianism: "Why is petitioning all-important? Because this lies at the very core of libertarianism" [1, p. 55]. He then explains that we need a theory of property rights, and that libertarians generally invoke a version of homesteading to explain the initial acquisition of property. He does not, however, give any reason why there cannot be any other rights.

\subsection{Reductio of the Risk Argument}

In my book, I argued that if there is even a reasonable chance that animal suffering matters, then we must end factory farming because the sheer quantity of suffering is so great. If, for example, there is even a $1 \%$ chance that animal suffering is as important as human suffering, then the expected value of a year's worth of factory farming is equal to that of a program that tortures 740 million people [2, pp. 1719].

Block's objection: there is a nonzero chance that almost any action might cause some horrific evil; e.g., maybe sitting on a chair causes agony to the chair [1, p. 61], maybe my being a vegan will shortly cause the painful death of everyone in the world by some unknown mechanism [1, p. 56], and so on. Thus, "anyone can make up any 'calculation' of this sort to prove a point" $[1, \mathrm{p} .56]$.

It is not clear what to make of this contention. Is Block saying that because it is possible to devise an incorrect expected utility calculation to support any course of action, we should never consider expected utility? This hardly seems cogent.

Perhaps Block thinks that there is a correct expected utility calculation supporting any course of action. But this thesis is contradictory, for it implies that both doing $\mathrm{A}$ and refraining from doing $\mathrm{A}$ maximize expected utility, for every A. Moreover, the thesis is false on its face. To make the argument that, e.g., sitting on chairs is wrong, one would need to do two things: (a) One would have to show that sitting on chairs was more likely to cause pain than to relieve pain, and that sitting was more likely to cause pain than refraining from sitting. One cannot show this sort of thing when one has simply made up an arbitrary hypothesis; there will always be an opposite arbitrary hypothesis to cancel it out. (b) One would have to argue that the expected harm to the chair outweighs the expected benefit we get from sitting on a chair. Block gives no indication of how someone would show that - which is not surprising since of course that is false.

In a footnote, Block invites the reader to make the probabilities (e.g., the probability that sitting on chairs causes pain) as low as one likes [1, p. 67n8]. It thus appears that Block thinks that the expected utility calculation would favor not sitting on chairs, no matter how low the probability is. This is not how expected utility calculations work; they are not insensitive to probabilities.

Perhaps Block's point is that my expected utility reasoning is analogous to his proposed expected utility arguments, namely, the arguments that would show (i) that I should give up veganism, and (ii) that we should avoid sitting on chairs.

If that is Block's point, I fail to see how his arguments are similar to mine, other than that both mention expected utility. I did not rely on any arbitrary hypotheses, nor any hypotheses with absurdly low probabilities, as Block's examples do. It is in fact overwhelmingly probable that farm animals experience pain and suffering, whereas it is incredibly improbable that chairs do. If one thinks that this isn't a relevant difference, then one does not understand expected utility.

\section{4. "Farming Is Good for Animals"}

Block worries that ending meat consumption would be bad for farm animals, because farm animals would no longer be raised and thus future generations of them would not have a chance to live at all [1, pp. 58-9]. 
I addressed this argument in my book, where I pointed out that the argument, if sound, would also support raising a special race of humans as slaves (or for food, or to torture for fun, etc.). About these slaves, it would also be true that they would not be alive at all if there were no such industry. One can even imagine that the slave traders in this industry - in between beating their slaves, packing them into train cars like sardines, and so on - would take a page from Professor Block and declare themselves friends of the slaves.

Block is aware of this objection, which he quotes from my book. What is his response? $\mathrm{He}$ agrees that slavery would still be "not okay. Of course not," then immediately adds, "But better than the alternative!", whereupon he simply restates the precise argument that my objection was an objection to.

It is difficult to understand what is going on here. Is Block agreeing with me or disagreeing? My objection was essentially this:

1. The argument in defense of the meat industry is analogous to the argument in defense of the slave industry (with people who are specifically bred to be slaves).

2. The argument in defense of the slave industry is unsound.

3. Therefore, the analogous argument in defense of the meat industry is unsound.

Which premise might Block be disputing? He makes no effort to dispute that the analogy is fair; indeed, he adds his own analogy apparently comparing our use of animals to a race of aliens coming and enslaving all mankind. So as far as I can tell, Block embraces premise (1).

He also endorses premise (2) when he agrees with me that it would not be okay to breed people to be slaves. He therefore must accept (3), which follows from (1) and (2). But then Block immediately goes on to simply restate the argument that we just showed to be unsound.

Perhaps Block actually disagrees with (2) but simply expressed himself misleadingly. Perhaps his view is that running a slavery industry, as described, would be permissible because it is "better than the alternative." If that is his view, then he could consistently claim that operating the meat industry in the status quo is also permissible. But this would be quite a remarkable view. I don't know what kind of libertarianism it is that endorses involuntary slavery. In any case, this seems like about as clear a reductio as the earlier one about torturing babies.

There are two more problems with Block's argument, apart from leading to an endorsement of slavery. First, the argument presupposes that our only options are (a) torturing animals horribly in factory farms, or (b) killing (or letting die?) all farm animals (including all members of their species?). (I'm not sure what Block thinks the second alternative is; he refers to vegans as "a genocide threat" to farm animals [1, p. 59], so I assume he thinks that we'd have to extinguish their species.) Here are two more alternatives: (c) treating farm animals humanely, (d) not raising any animals for food but allowing their species to exist in the wild. (There are in fact wild chickens, and there used to be wild cows.) Block's argument for (a) is that it is better than (b). But he makes no attempt to show that (a) is the best possible alternative. If there is any option that is better than the horrible option (a), then (a) is clearly impermissible.

Here is the other problem. As mentioned in my book, the lives of factory farm animals appear to be so miserable that it would be much better if no such lives existed. To see my point, imagine that I told you that it was possible to greatly expand the human population of the Earth. We could have ten times as many people! To make this happen, what we have to do is create 70 billion new people who would spend their lives jammed into cages or barns where they could barely move, sitting in their own excrement all day. Most would never see the light of day. Many of these people would be living in buildings where the floor was covered in ammonia, so that they would be breathing ammonia fumes at all times. Once in each person's life, someone would come by and chop a small body part off the person, without anesthetic. Occasionally, someone would come by and just beat one of the people for 
the fun of it. The women would be used to breed more people, but the babies would be forcibly separated from their mothers at birth. Finally, after lives of just a few months on average, someone would come and cut these people's throats or bash in their skulls.

I have it in my power, I tell you, to bring about that world, but I will only do it if you tell me to. What say you?

That is analogous to Block's idea that we should continue to create billions more animals to live and die in factory farms every year. Everything I stipulated in that scenario is accurate to the conditions in factory farms. ${ }^{3}$ For my part, I do not find this difficult to evaluate. Obviously, you should say "No, do not create the 70 billion miserable lives."

\section{5. “Animals Kill Other Animals”}

Block cites the fact that chickens sometimes kill and even eat other chickens. He proudly contrasts humans, who very rarely eat members of our own species [1, p. 59].

I am not sure what point Block is trying to make. Is he arguing that because chickens sometimes eat other chickens, it is morally permissible for us to torture and kill chickens in order to experience the pleasure of eating their flesh? The logic of this inference escapes me.

Perhaps the idea is that chickens are so vicious that they deserve to suffer and die? Human beings, however, have been killing each other, torturing, raping, robbing, and so on, for all of human history. If anything, humans seem far worse than most animals. By Block's logic, then, raising humans in factory farms would be fine.

\section{6. "Rights Imply Responsibilities"}

Block says that "with rights come responsibilities" [1, p. 59]. Since animals do not have any responsibilities, presumably, they cannot have rights.

Block, however, gives no argument for his premise. (A popular catch phrase is not an argument.) Remember what we are talking about here. We are talking about inflicting severe pain and suffering, followed by death, on other beings for our own relatively minor pleasure. It must be explained why that is acceptable. Now consider this explanation: "The creatures we are torturing and killing don't have responsibilities, so everything is fine." I fail to see the logic here.

Again, Block's assumptions lead to absurdity. Since babies, severely mentally retarded people, and severely mentally ill people lack responsibilities, they must have no rights; hence, we may torture and kill them at will.

Perhaps Block would deny that it is acceptable to torture and kill other beings merely because they lack responsibilities. Perhaps he would say only that such torture is not a rights violation, but it is still wrong for some other reason. But then he would be granting my main point: factory farming is wrong, and it's wrong to buy the products that come from that source.

\section{7. "Utilitarianism Supports Rape”}

Block worries that a purely hedonistic (concerned only with pleasure and pain) philosophy would lend support to rape: as long as the rapist's pleasure is greater than the victim's pain, rape would be permissible [1, p. 61]. To avoid this conclusion, he thinks, we should adopt a rights-based, libertarian philosophy.

This argument is off-target; it does not address anything that I have ever said or thought. I did not advance a purely hedonistic philosophy, nor did I suggest that no one has any rights. I simply 
argued that we should not inflict severe pain and suffering on other creatures for the sake of minor benefits to ourselves. This does not entail that no one has rights, nor did I in any way suggest that.

\section{8. "Experts Can Be Wrong”}

In the Dialogues, I mentioned that most experts who review the ethical arguments concerning vegetarianism agree that they are compelling [2, p. 69]. Block, however, objects that putative experts are sometimes wrong; for instance, humanities professors often wrongly support minimum wage laws [1, p. 61].

There are two problems with this. First, humanities professors are not experts on economics, so this is not an example of experts getting things wrong. That is a minor problem, though, because we could surely find an example of actual experts getting something wrong.

Here is the second problem. The fact that experts are not infallible does not imply that you are reasonable to disregard their judgments - unless of course your own non-expert judgment is infallible. For example, health experts used to believe that fat in general was bad for you. Now it is thought that only some fats are bad while others are good. So medical experts are fallible. It does not follow from this that, if your doctor gives you some advice, you should ignore it.

Now, unlike Block's example of humanities professors talking about economics, ethics professors who work on animal ethics actually are experts on that subject. They tend to be highly intelligent; to be well-informed about the relevant ideas, distinctions, and arguments in the field; and to have spent a long time thinking about the subject. If you don't think those characteristics increase one's odds of getting to the truth, then you must be a radical skeptic, because it is hard to imagine what could possibly help one to get to the truth if those things don't make any difference. Of course, ethics professors are fallible like all humans, but that's no reason for disregarding their judgment - again, not unless you, unlike all the experts, have some unerring access to the truth.

\subsection{Shutting Down Modern Society}

Finally, Block worries that my ethical views might require us to shut down modern society. He notes that deep mining, dams, nuclear power, and windmills all cause some amount of suffering and/or death. He might have added that the same is true of all technology.

This would be a strong objection if my thesis in the book was, "All activities that ever cause any harm at all are impermissible." Fortunately, I have never held such an absurd view, and neither, to the best of my knowledge, does anyone else. (If someone held that view, I think the most obvious objection would be that the view entails that everything whatsoever is impermissible, so we'd all be obligated to be completely passive, not even breathing, until we die.)

I argued that factory farming is wrong because of the enormous amount of pain and suffering it causes, for the sake of trivial benefits for ourselves. This does not imply, nor did I suggest, that everything that causes any suffering or death at all is wrong. We are not limited to the two options of holding either (a) it is always wrong to cause any amount of suffering for any reason, or (b) it is always perfectly permissible to cause any amount of suffering for any reason.

I have not advanced a complete theory of all the possible conditions in which actions are right or wrong, or even in which causing suffering is right or wrong. No doubt Block will be disappointed by this. Be that as it may, we do not need to entertain any such theory, because the case at hand is not a difficult case. We are talking about factory farming, and buying the products that it produces. We only have to answer whether that is permissible.

Well, if ever it is wrong to cause suffering, factory farming is about the best example one can think of (that and torturing babies for fun, as discussed earlier). Surely we humans would need a good 
reason for inflicting, every few years, more suffering than all the suffering in all of human history on other creatures. Do we have such a good reason? To answer that, we do not need to first write down a list of every possible good reason that anyone could ever have. All we have to do is look at the actual reasons that people have given in this case. When we do that, we find some of the most obvious non sequiturs, absurdities, rationalizations, and attempts at distraction that you will find in all of human discourse.

\section{Opposing Suffering}

After all I have said, you might assume that Walter Block and I have opposite views on the subject of animal ethics. Not so - at least, not as opposite as they could be. For Block explicitly embraces my main premise:

If I had to summarize this book in three words it would be: "stop the suffering." I acknowledge that I, too, support this plea. Who but a malevolent, malicious person, a sadist, would actually support anguish, whether for humans or non-humans[?] There is altogether too much misery in the world, and any lessening of it has to be counted on the asset side of the ledger [1, p. 60].

I join [Huemer] in opposing suffering, whether for man or beast. The world has far too much misery. Any reduction is to be fervently welcomed [1, p. 63].

How is it possible that those sentiments are not swiftly followed by a zealous agreement with me on the abomination of factory farming and the moral unacceptability of patronizing that industry? How can a person oppose suffering yet still find it acceptable to continually cause enormous amounts of it for the sake of minor benefits for ourselves?

As far as I can tell, the answer is, "By misdirection." When Block appears just about to embrace my main conclusions, as in the above two quotations, he instead turns aside and starts discussing some other issue. He follows the first quotation above with a discussion of how it is permissible to cause suffering to convicted criminals who deserve punishment. He does not go on to explain how farm animals are like convicted criminals; he simply moves on once the issue of retributivism has diverted attention from the problem with meat consumption. He follows the second quotation above with a comment about how he doubts that it would be just to imprison meat-eaters and farmers. He never explains how buying meat from factory farms is acceptable, though. Again, once the issue of just or unjust imprisonment has distracted Block's attention, he is able to move on without addressing the main issue.

That is generally how Block's critique goes. In case this hasn't been made sufficiently clear, the central thesis of my book was that it is morally wrong for us, right now, to buy products from factory farms, as almost everyone is doing. Almost none of Block's critique bears on that; almost none of it could be seen as even attempting to explain why it would be acceptable to buy factory farm products. (See especially the arguments addressed in sections 3.1, 3.2, 3.3, 3.6, 3.7, 3.8, and 3.9 above.)

Block never disputes the cruelty of factory farms or the enormous amount of suffering they are causing. Nor does he dispute that we should reduce suffering; again, see the two quotations above. Perhaps Block would say that, in the above two quotations, he only meant that he supports reducing suffering as long as the cost of doing so is not too high. This could be a rational position, depending on how one understands "too high." Perhaps if the cost would be giving up a much larger amount of pleasure, then the cost is too high. Perhaps even if it requires giving up a slightly larger amount of pleasure, one could claim that the cost was too high (that, at any rate, is what the utilitarians would 
say). But suppose the cost is giving up a little bit of pleasure for ourselves, for the sake of averting thousands of times greater suffering - as is in fact the case for ethical vegetarianism. If one still says that that is too high a cost, then one cannot seriously claim to be against suffering.

\section{References}

1. Block, W. E. On Huemer on Ethical Veganism, Studia Humana 9, 2020, pp. 53-68.

2. Huemer, M. Dialogues on Ethical Vegetarianism, New York: Routledge, 2019.

3. Rachels, S. Vegetarianism, in T. L. Beauchamp and R. G. Frey (eds.), Oxford Handbook of Animal Ethics, pp. 877-905, Oxford: Oxford University Press, 2011.

\section{Notes}

1. See [1], responding to [2].

2. That, incidentally, is not correct. Masochists desire pain in sexual interactions as a means to increasing arousal and thus enhancing sexual enjoyment. Block also mistakenly conflates pain with suffering. It is possible to enjoy pain in certain contexts, but it is not possible to enjoy suffering, as this is a contradiction in terms. By definition, if one is enjoying an experience, one is not suffering.

3. For more on factory farm conditions, see [3, pp. 877-83]. 